\title{
DAMPAK PT. SARULLA OPERATIONAL LIMITED (SOL) PANAS BUMI TERHADAP EKONOMI DAN LINGKUNGAN MASYARAKAT KECAMATAN PAHAE JULU KABUPATEN TAPANULI UTARA
}

\author{
Dina Simatupang ${ }^{1}$, Yudi Antomi ${ }^{2}$, Triyatno ${ }^{2}$ \\ Program Studi Geografi \\ Fakultas Ilmu Sosial Universitas Negeri Padang \\ Email : dinasmtpng@gmail.com
}

\begin{abstract}
ABSTRAK
Penelitian ini bertujuan untuk mengetahui (1) dampak PT. Sarulla Operational Limited (SOL) Panas Bumi terhadap ekonomi di Kecamatan Pahae Julu, (2) untuk mengetahui dampak PT. Sarulla Operational Limited (SOL) Panas Bumi terhadap lingkungan (pencemaran air) di Kecamatan Pahae Julu. Metode yang digunakan dalam penelitian ini adalah metode penelitian deskriptif kuantitatif. Penelitian ini menggunakan data primer dan data sekunder. Populasi dalam penelitian ini adalah Daerah Aliran Sungai Batang Toru dan masyarakat Kecamatan Pahae Julu dari 19 desa yang berjumlah 12.343 jiwa. Penelitian ini dilakukan dengan metode survei dan wawancara. Hasil penelitian menunjukkan bahwa 1) ada dampak positif dari keberadaan PT. Sarulla Operational Limited (SOL) Panas Bumi terhadap ekonomi masyarakat seperti di bidang pekerjaan masyarakat memiliki peluang menambah penghasilan seperti membuka warung, rumah makan, kontrakan/kos-kosan, jual jasa sopir dan laundry sehingga dengan ini pendapatan masyarakat meningkat, 2) berdasarkan hasil penelitian mengenai lingkungan (pencemaran air) yang dilakukan dengan uji laboratorium, hasil penelitian menunjukkan bahwa air Sungai Batang Toru yang ada di sekitar PT. Sarulla Operational Limited (SOL) Panas Bumi tergolong tercemar dengan parameter yang diuji yaitu $\mathrm{pH}$, BOD, DO, Posfat dan COD dan Nitrat tergolong tidak tercemar.
\end{abstract}

\section{Kata Kunci : Dampak Ekonomi, Dampak Lingkungan}

\begin{abstract}
This study aims to determine (1) the impact of PT. Sarulla Operational Limited (SOL) Geothermal on the economy in Sub Pahae Julu, (2) to know the impact of PT. Sarulla Operational Limited (SOL) Geothermal on the environment (water pollution) in District Pahae Julu. The method used in this research is descriptive quantitative research methods.This study uses primary data and secondary data. The population in this study is the Watershed District of Batang Toru and Pahae Julu community of 19 villages totaling 12343 inhabitants. The research was conducted by survey and interview. The results showed that 1) there is a positive impact of the presence of PT. Sarulla Operational Limited (SOL) Geothermal towards economic communities such as in the field of community work have the opportunity to increase revenue such as small store, restaurants, rent/boarding houses, selling services of a driver and laundry so that these people's income increases, 2) based on the results of research on the environment (water pollution) conducted by a laboratory test, the results showed that the waters of the Batang Toru around PT. Sarulla Operational Limited (SOL) Geothermal classified as contaminated with the parameters tested, namely pH, BOD, DO, Phosphate and Nitrate COD and relatively uncontaminated.
\end{abstract}

Keywords: Economic Impact, Environmental Impact 


\section{PENDAHULUAN}

Manusia dan kegiatan industri menghasilkan pelepasan berbagai polutan ke lingkungan akuatik (air) yang mengancam kesehatan penduduk dan merusak kualitas lingkungan dengan membuat kualitas air tidak layak. Pencemaran air adalah masalah utama dalam konteks global (Yang Gancai dan C Youngguan, 2004).

Telah dikemukakan bahwa penyebab kematian dan penyakit di seluruh dunia adalah bahwa kecelakaannya untuk kematian dan penyakit dan menyebabkan kematian dan lebih dari 14.000 orang setiap hari (World Bank, 1990). Pencemaran air permukaan dapat mengancam manusia, hewan dan ekosistem (Adamu Mustapha dan Balabe Usman, 2014).

Pada era globalisasi ini pertumbuhan perusahaan semakin pesat. Perusahaan yang merupakan salah satu instrument perekonomian di negara manapun sangat besar peranannya dalam gerak ekonomi. Namun, di sisi lain perusahaan tidak terlepas dari masalah-masalah fisik dan sosial yang ada. Permasalahan yang ditimbulkan perusahaan tidak hanya segala sesuatu yang berhubungan dengan kegiatan kinerja atau proses produksi, akan tetapi banyak juga hal lain secara tidak langsung akan mempengaruhi aktivitas kerja dalam perusahaan tersebut.
Misalnya masalah upah atau gaji, kesejahteraan, kerusakan lingkungan, peraturan organisasi yang ada dalam perusahaan, dan lain-lain. Perusahaan didirikan dengan maksud untuk mencapai tujuan-tujuan tertentu. Dalam mencapai tujuan tersebut, perusahaan selalu berinteraksi dengan lingkungannya sebab lingkungan memberikan andil dan kontribusi bagi perusahaan.

Selain masalah akut pencemaran air di negara-negara berkembang, negara-negara industri terus berjuang dengan masalah polusi juga (Sachezcholiz dan Daurtz, 2005).

Air biasanya disebut sebagai tercemar ketika itu terganggu oleh kontaminan antropogenik dan baik tidak mendukung penggunaan manusia seperti melayani sebagai air minum dan atau mengalami pergeseran pasar dalam kemampuannya untuk mendukung komunitas biotik penyusunnya seperti ikan, fenomena alam seperti gunung berapi, mekar alga, badai dan gempa bumi juga menyebabkan perubahan besar dalam kualitas air dan status ekologi air (Farid, 2002).

Penelitian baru tentang kadar timah dalam minum menunjukkan bahwa kadar timah dalam air minum kita terus terlalu tinggi dan mungkin lebih berbahaya daripada yang diperkirakan sebelumnya. (FEPA, 1991). 
Kriteria kualitas air minum harus didasarkan pada penelitian yang didokumentasikan efek kesehatan penerimaan konsumen, menunjukkan teknik pengobatan dan manajemen utilitas yang efektif. Kriteria minimum harus seperti yang didefinisikan oleh federal, peraturan negara bagian dan provinsi yang mempertimbangkan pertimbangan kesehatan dan biaya yang sesuai (Everpure, 1997).

Pencemaran air atau kontaminasi juga menempatkan sumber daya lain yang berisiko, perikanan dan sumber daya lahan misalnya, telah terpengaruh secara signifikan. Kontribusi terhadap pencemaran air termasuk zat yang diambil dari udara, endapan dari erosi tanah, pupuk dan pestisida kimia, limpasan dari tangki septik, aliran keluar dari makanan ternak, limbah kimia (beberapa beracun) dari industri, dan limbah dan limbah perkotaan lainnya, dari kota-kota dan negara. (Fewtrell dan Clofford, 2004).

Air hujan yang terkontaminasi dicuci dari tempat parkir, jalan dan jalan raya, yang disebut limpasan perkotaan, kadang-kadang termasuk dalam kategori pencemaran sumber nonpoint. (Hung dan Shaw, 2004, Khan, 1997).
Contoh polusi sumber titik (pipa atau selokan) termasuk pembuangan dari pabrik pengolahan limbah, pabrik atau saluran badai kota (Harrington et al, 1989; HertzPicciotto et al, 2000 ). Minyak dan anti beku yang bocor dari kendaraan juga mencemari air. Anak-anak dan bayi yang baru lahir kebanyakan dipengaruhi oleh konsekuensi pencemaran air yang dapat dilihat dari tingginya angka kematian bayi di negara tersebut (Ilegbodu dkk, 1987).

Di sisi lain, Jimoh, 2007 menyatakan bahwa kerusakan kesehatan telah meningkat secara serius karena ketekunan deklinasi produktivitas manusia dan hewan. Beberapa fasilitas industri, menghasilkan limbah domestik biasa yang dapat menginstal sistem praperawatan untuk menghilangkan komponen beracun dan kemudian mengirim air limbah yang diolah sebagian ke sistem kota atau industri yang menghasilkan volume besar pada sistem perawatan lokasi (Esrey et al, 1991). Pengelolaan limbah menjadi semakin kompleks karena peningkatan populasi manusia, revolusi industri dan teknologi (Akinbile dan Yussoff (2011). 


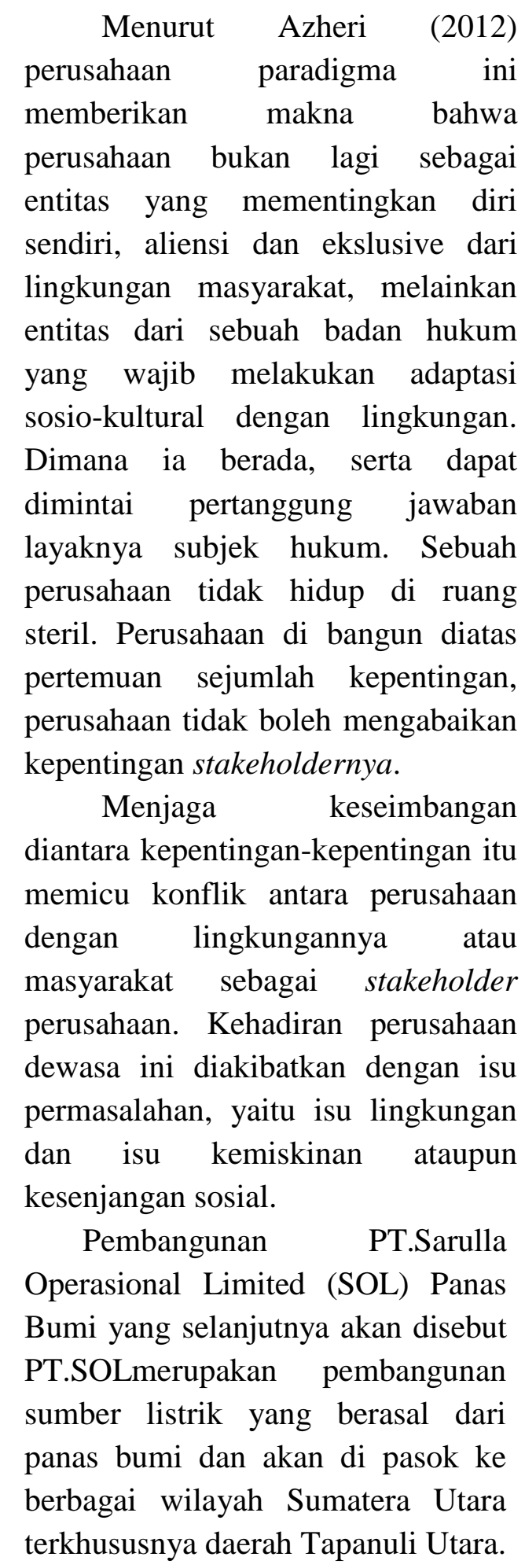

Pada dasarnya Kecamatan Pahae Julu merupakan masyarakat yang jauh dari kata makmur, namun mereka masih bisa memenuhi kebutuhan kesehariannya.

Dampak pembangunan yang merugikan masyarakat Kecamatan Pahae Julu semakin banyak dijumpai masyarakat, seperti peralihan fungsilahan, kerusakan lingkungan dan timbulnya konflik sosial. Disamping itu, masyarakat yang berada di Kecamatan Pahae Julu juga diuntungkan dari berbagai aspek, mulai dari kondisi perekonomian yang semakin membaik, lapangan kerja yang semakin banyak di jumpai di Kecamatan Pahae Julu yang menjadikan berkurangnya angka penggangguran, peningkatan dari sisi pendidikan dan lain-lain.

Penduduk Kecamatan Pahae Julu yang banyak bekerja sebagai petani sangat ditunjang oleh lingkungan yang luas dan memiliki curah hujan yang cukup tinggi, sehingga mendukung daerah ini sebagai daerah pertanian. Namun seiring berjalannya pembangunan PT.SOL, peralihan fungsi lahan kerap terjadi di daerah mereka. Lahan yang sebelumnya dijadikan sebagai lahan pertanian kini beralih fungsi sebagai lokasi pembangunan PT.SOL. 
Dampak lingkungan yang dirasakan oleh dari hadirnya PT.SOL adalah yaitu pencemaran air, polusi udara, dan lain-lain.

Badan Lingkungan Hidup Amerika Serikat mengatakan bahwa sumber polusi sebagai berikut: "Sumber kontaminan (polutan) dapat bersifat spesifiklokasi (sumber titik) atau tidak tentu / menyebar (sumber tidak jelas / tidak jelas).

Pencemaran air terjadi akibat pembuangan limbah cair panas bumi (lumpur panas bumi) yang dihasilkan PT. SOL ke sungai yang di kenal masyarakat Tapanuli Utara dengan nama sungai Batang Toru sehingga menyebabkan kualitas air menjadi menurun. Hal ini juga berdampak kepada aktivitas masyarakat dalam memanfaatkan sungai Batang Toru yang sudah ikut tercemar oleh limbah PT. SOL. Selain itu pencemaran sungai ini juga akan berdampak pada ekosistem yang terdapat di sekitar sungai Batang Toru, dimana kawasan ini merupakan kawasan lindung yang sangat penting dalam melindungi berbagai macam flora maupun fauna.

Adapun tujuan penelitian ini adalah :

1. Untuk mengetahui dampak PT. SOL terhadap ekonomi di Kecamatan Pahae Julu

2. Untuk mengetahui dampak PT. SOL terhadap pencemaran air di Kecamatan Pahae Julu.

\section{METODE PENELITIAN}

Jenis penelitian ini adalah penelitian deskriptif kuantitatif. Tujuan dari penelitian deskriptif ini adalah menggambarkan, melukiskan, sifat-sifat serta hubungan antar fenomena yang diselidiki.

Lokasi penelitian ini dilakukan di Kecamatan Pahae Julu, Kabupaten Tapanuli Utara. Waktu pelaksanaan penelitian dilaksanakan dalam jangka waktu dua bulan yaitu, Desember 2017-Januari 2018.

Populasi dalam penelitian ini adalah Sungai Batang Toru dan masyarakat Kecamatan Pahae Julu dari 19 desa yang berjumlah 12.343 jiwa.

Dalam penelitian ini teknik pengambilan sampel yang digunakan adalah teknik proportional random sampling yaitu menentukan anggota sampel dengan mengambil wakilwakil dari tiap-tiap kelompok yang ada dalam populasi yang jumlahnya disesuaikan dengan jumlah anggota subjek yang ada di dalam masingmasing kelompok tersebut.

Dengan ketentuan sampel air di Sungai Batang Toru adalah penetapan 4 stasiun yakni stasiun 1 sebelum perusahaan (kontrol), stasiun 2 terdapat aktivitas perusahaan (PT.SOL), stasiun 3 terdapat aktivitas domestik (permukiman penduduk) dan stasiun 4 terdapat aktivitas pertanian atau perkebunan masyarakat.

Data yang digunakan dalam penelitian ini adalah data primer 
dan data sekunder. Data primer dalam penelitian ini adalah berupa hasil wawancara dan pengambilan sampel di lokasi penelitian. Datasekunder penelitian ini diperoleh dari Badan Perencanaan Pembangunan Daerah (BAPPEDA) Kabupaten Tapanuli Utara dan Badan Pusat Statistik (BPS) Kabupaten Tapanuli Utara.

Teknik analisis data yang di gunakan dalam penelitian sesuai dengan rumusan masalah adalah :

1. Dampak PT.SOL terhadap ekonomi.

Sesuai dengan tujuan penelitian maka data yang diperoleh diolah dengan menggunakan analisa deskriptif dengan rumus presentasi untuk melihat masing-masing variabel menggunakan rumus sebagai berikut :

$$
\mathrm{P}=\frac{f}{N} \times 100 \%
$$

Keterangan :

$\mathrm{P}$ : Persentase

f : Frekuensi jawaban

responden

$\mathrm{N}$ : Jumlah Responden

(Sumber: Sudjana, 2007)

2. Dampak PT.SOL terhadap lingkungan (Pencemaran Air).

Teknis analisis data yang digunakan dalam penelitian ini adalah semua parameter kualitas air yang diperoleh dan dibandingkan dengan baku mutu air menurut Peraturan Pemerintah Nomor 82 Tahun 2001 Kelas II dapat dilihat pada table dibawah ini :

Tabel 1

Peraturan Pemerintah Nomor 82 Tahun 2001

Tentang Pengelolaan Kualitas Air dan Pengendalian Pencemaran Air

\begin{tabular}{|l|c|c|c|c|c|}
\hline \multirow{2}{*}{ Parameter } & Satuan & \multicolumn{5}{|c|}{ Kelas } \\
\cline { 3 - 6 } & & I & II & III & IV \\
\hline FISIKA & & & & & \\
\hline
\end{tabular}




\begin{tabular}{|l|c|c|c|c|c|}
\hline Temperatur & ${ }^{\circ} \mathrm{C}$ & deviasi 3 & deviasi 3 & deviasi 3 & deviasi 5 \\
\hline Residu Terlarut & $\mathrm{mg} / \mathrm{L}$ & 1000 & 1000 & 1000 & 2000 \\
\hline Residu Tersuspensi & $\mathrm{mg} / \mathrm{L}$ & 50 & 50 & 400 & 400 \\
\hline $\begin{array}{l}\text { KIMIA } \\
\text { ANORGANIK }\end{array}$ & & & & & \\
\hline $\mathrm{pH}$ & & $6-9$ & $6-9$ & $6-9$ & $5-9$ \\
\hline BOD & $\mathrm{mg} / \mathrm{L}$ & 2 & 3 & 6 & 12 \\
\hline $\mathrm{COD}$ & $\mathrm{mg} / \mathrm{L}$ & 10 & 25 & 50 & 100 \\
\hline DO & $\mathrm{mg} / \mathrm{L}$ & 6 & 4 & 3 & 0 \\
\hline Total fosfat sebagai $\mathrm{P}$ & $\mathrm{mg} / \mathrm{L}$ & 0,2 & 0,2 & 1 & 5 \\
\hline $\mathrm{NO}_{3}$ sebagai $\mathrm{N}$ & $\mathrm{mg} / \mathrm{L}$ & 10 & 10 & 20 & 20 \\
\hline $\mathrm{NH}_{3}-\mathrm{N}$ & $\mathrm{mg} / \mathrm{L}$ & 0,5 & $(-)$ & $(-)$ & $(-)$ \\
\hline Arsen & $\mathrm{mg} / \mathrm{L}$ & 0,05 & 1 & 1 & 1 \\
\hline Kobalt & $\mathrm{mg} / \mathrm{L}$ & 0,2 & 0,2 & 0,2 & 0,2 \\
\hline Barium & $\mathrm{mg} / \mathrm{L}$ & 1 & $(-)$ & $(-)$ & $(-)$ \\
\hline Boron & $\mathrm{mg} / \mathrm{L}$ & 1 & 1 & 1 & 1 \\
\hline Selenium & $\mathrm{mg} / \mathrm{L}$ & 0,01 & 0,05 & 0,05 & 0,05 \\
\hline Kadmium & $\mathrm{mg} / \mathrm{L}$ & 0,01 & 0,01 & 0,01 & 0,01 \\
\hline Khrom $(\mathrm{VI})$ & $\mathrm{mg} / \mathrm{L}$ & 0,05 & 0,05 & 0,05 & 1 \\
\hline Tembaga & $\mathrm{mg} / \mathrm{L}$ & 0,02 & 0,02 & 0,02 & 0,2 \\
\hline Besi & $\mathrm{mg} / \mathrm{L}$ & 0,3 & $(-)$ & $(-)$ & $(-)$ \\
\hline Timbal & $\mathrm{mg} / \mathrm{L}$ & 0,03 & 0,03 & 0,03 & 1 \\
\hline
\end{tabular}

Sumber : PP No. 82 Tahun 2001

\section{HASIL DAN PEMBAHASAN}

\section{Ekonomi (Pekerjaan dan}

Pendapatan)

a. Pendidikan Terakhir

Pendidikan yang dimaksud adalah pendidikan terakhir dari kepala keluarga yang dibagi menjadi empat kelompok yaitu tidak bersekolah, SD, SMP/Sederajat, SMA/Sederajat dan Perguruan Tinggi. Persentase tingkat pendidikan ini disajikan pada tabel 8 di bawah ini :

Tabel 2

Pendidikan Terakhir

\begin{tabular}{|c|c|c|c|}
\hline No & $\begin{array}{c}\text { Pendidikan } \\
\text { Kepala Rumah } \\
\text { Tangga }\end{array}$ & $\begin{array}{c}\text { Jumlah } \\
\text { KK } \\
(\mathrm{F})\end{array}$ & $\%$ \\
\hline 1 & Tidak & 10 & 12 \\
\hline
\end{tabular}

\begin{tabular}{|r|l|r|r|}
\hline & Bersekolah & & \\
\hline 2 & SD & 20 & 23 \\
\hline 3 & SMP/Sederajat & 31 & 36 \\
\hline 4 & SMA/Sederajat & 14 & 16 \\
\hline 5 & PerguruanTinggi & 11 & 13 \\
\hline & Jumlah & 86 & 100 \\
\hline
\end{tabular}

Sumber: Pengolahan data primer 2018

Hasil penelitian menunjukkan bahwa responden rata-rata dengan tingkat tidak bersekolah yaitu sebesar 10 orang (12\%), tingkat SD 20 orang (23\%), tingkat SMP/Sederajat 31 orang (36\%),tingkat SMA/Sederajat 14 orang (16\%) dan tingkat perguruan tinggi 11 orang (13\%). Pada umumnya tingkat pendidikan tidak sekolah, SD, SMP/Sederajat dan sebagian SMA/Sederajat bekerja sebagai petani sedangkan untuk tingkat pendidikan perguruan tinggi 
bekerja sebagai pegawai negeri dan swasta.

\section{b. Jumlah Anggota Keluarga}

Jumlah anggota keluarga responden dikelompokkan menjadi dua bagian yaitu jumlah anggota keluarga $<5$ orang dan jumlah anggota keluarga $>5$ orang. Jumlah anggota keluarga dapat dilihat pada tabel di bawah ini :

Tabel 3 JumlahAnggotaKeluarga

\begin{tabular}{|c|c|r|r|}
\hline No & $\begin{array}{c}\text { Jumlah } \\
\text { Anggota } \\
\text { Keluarga }\end{array}$ & $\begin{array}{c}\text { Jumlah } \\
\text { KK } \\
\text { (F) }\end{array}$ & $\%$ \\
\hline 1 & $<5$ & 22 & 26 \\
\hline 2 & $>5$ & 64 & 74 \\
\hline & Jumlah & 86 & 100 \\
\hline
\end{tabular}

Sumber: Pengolahan data primer 2018

Jumlah anggota keluarga merupakan salah satu faktor yang dapat mempengaruhi pengeluaran, semakin banyak jumlah anggota keluarga tentu pemenuhan akan kebutuhan juga akan meningkat. Hasil penelitian menunjukkan bahwa 22 orang (26\%) memiliki jumlah anggota keluarga $<5$ sedangkan 64 orang (74\%) memiliki jumlah

Tabel 4

Jenis Pekerjaan

\begin{tabular}{|l|r|r|l|r|r|}
\hline \multicolumn{2}{|c|}{ Sebelum PT. SOL berdiri } & \multicolumn{2}{c|}{ Sesudah PT. SOL berdiri } \\
\hline \multicolumn{1}{|c|}{ Jenis pekerjaan } & F & \multicolumn{1}{c|}{$\%$} & Jenis pekerjaan & \multicolumn{1}{c|}{ F } & \multicolumn{1}{c|}{ ( } \\
\hline Petani & 61 & 71 & Rumah makan & 8 & 9 \\
\hline Pegawai Negeri & 6 & 7 & Warung & 16 & 19 \\
\hline Pegawai Swasta & 5 & 6 & Laundry & 9 & 8 \\
\hline Wiraswasta & 14 & 16 & Sopir & 10 & 12 \\
\hline & & & Kontrakan/kos-kosan & 36 & 42 \\
\hline & & & Tetap & 86 & 100 \\
\hline
\end{tabular}

Sumber: Pengolahan data primer 2018 adanya PT. SOL banyak masyarakat kurang mampu dalam memenuhi kebutuhan hidupnya, namun setelah adanya PT. SOL masyarakat bisa memiliki peluang untuk menambah penghasilan.

c. Jenis Pekerjaan

Berdasarkan tujuan dari penelitian yaitu untuk melihat dampak PT. SOL terhadap ekonomi di Kecamatan Pahae Julu. Dampak ekonomi sebelum maupun sesudah PT. SOL berdiri dilihat dari jenis pekerjaan dapat diamati tabel dibawah ini : 
Berdasarkan tabel di atas dapat dijelaskan bahwa pendapatan dan pekerjaan masyarakat di Kecamatan Pahae Julu, jika dilihat dari jenis pekerjaan masyarat sebelum dan sesudah PT. SOL berdiri maka dapat dijelaskan bahwa adapun jenis pekerjaan sebelum PT SOL berdiri ini adalah Petani sebanyak 61 orang $(72 \%)$, pegawai negeri sebanyak 6 orang $(7 \%)$, pegawai swasta sebanyak 5 orang (6\%) dan wiraswasta 14 orang (17\%). Dari tabel dan penjelasan diatas dapat disimpulkan bahwa pada umumnya adapun pekerjaan masyarakat di Kecamatan Pahae Julu sebelum PT SOL berdiri adalah petani yaitu sebanyak 61 orang (72\%).

d. Pekerjaan Setelah PT. SOL berdiri

Ada sebagian masyarakat yang ada di Kecamatan Pahae Julu yang memiliki pekerjaan setelah PT. SOL berdiri yang terdapat pada tabel diatas seperti membuka rumah makan, warung, jasa laundry, sopir, jasa kontrakan/ kos-kosan. Penjelasan dapat dilihat pada tabel di bawah ini :

Tabel 5

Jawaban Responden Setelah PT. SOL Berdiri

\begin{tabular}{|c|r|c|}
\hline Keterangan & F & $\%$ \\
\hline IYA & 50 & $58 \%$ \\
\hline TIDAK & 36 & $42 \%$ \\
\hline
\end{tabular}

Sumber: Pengolahan data primer 2018

Berdasarkan tabel di atas, maka dapat dijelaskan bahwa sebanyak 50 orang (58\%) masyarakat yang ada di Kecamatan Pahae Julu ada memiliki pekerjaan sesudah PT. SOL berdiri, dan sisa nya 36 orang $42 \%$ tidak memiliki pekerjaan atau masih pada pekerjaan lama nya.

\section{e. Rata-rata Pendapatan}

Berdasarkan tujuan dari penelitian yaitu untuk melihat dampak PT. SOL terhadap ekonomi di Kecamatan Pahae Julu. Dampak ekonomi sebelum maupun sesudah PT. SOL berdiri dilihat dari jenis rata-rata pendapatan masyarakat/bulan dapat diamati tabel di bawah ini :

Tabel 6

Rata-rata pendapatan/bulan

\begin{tabular}{|l|r|r|l|r|r|}
\hline \multicolumn{2}{|c|}{ Sebelum PT. SOL berdiri } & \multicolumn{3}{c|}{ Sesudah PT. SOL berdiri } \\
\hline \multicolumn{1}{|c|}{ Pendapatan } & \multicolumn{1}{|c|}{$\%$} & Pendapatan & F & \multicolumn{1}{c|}{} \\
\hline <2 Juta & 67 & 78 & <2 Juta & 31 & 36 \\
\hline 2 Juta > 4 juta & 13 & 15 & 2 Juta > 4 juta & 18 & 21 \\
\hline Lebih dari 4 juta & 6 & 7 & Tidak ada pendapatan & 37 & 43 \\
\hline \multicolumn{1}{|c|}{ Jumlah } & 86 & 100 & Jumlah & 86 & 100 \\
\hline
\end{tabular}

Sumber: Pengolahan data primer 2018

Berdasarkan tabel diatas

dapat dijelaskan bahwa pendapatan

dan pekerjaan masyarakat di
Kecamatan Pahae Julu, jika dilihat dari jenis rata-rata pendapatan masyarat sebelum dan sesudah PT. 
SOL berdiri maka dapat dijelaskan bahwa adapun jenis pekerjaan sebelum PT SOL berdiri ini adalah kurang dari 2 juta sebanyak 67 orang (78\%), 2 juta sampai 4 juta sebanyak 13 orang (15\%) dan sisanya diatas 4 juta sebanyak 6 orang (7\%). Sesudah PT. SOL berdiri sebagian masyarakat yang memiliki pekerjaan setelah PT. SOL berdiri juga memiliki penghasilan tambahan kurang dari juta 2 juta sebanyak 31 orang (36\%) penghasilan 2 juta sampai 4 juta sebanyak 18 orang (21\%) sisanya 37 orang lagi $(43 \%)$ lagi tidak memiliki penghasilan setelah PT. SOL berdiri.

f. Pendapatan Sampingan Untuk Kebutuhan

Berdasarkan tujuan dari penelitian yaitu untuk melihat dampak PT. SOL terhadap ekonomi di Kecamatan Pahae Julu. Dampak ekonomi sebelum maupun setelah PT. SOL berdiri dilihat dari pendapatan terhadap kebutuhan dapat diamati tabel di bawah ini :
Tabel 7

Pendapatan Sampingan Terhadap

Kebutuhan

\begin{tabular}{|l|r|r|}
\hline \multicolumn{1}{|c|}{ Keterangan } & \multicolumn{1}{c|}{ F } & \multicolumn{1}{c|}{$\%$} \\
\hline Cukup & 66 & 77 \\
\hline Kurang Cukup & 20 & 23 \\
\hline Jumlah & 86 & 100 \\
\hline
\end{tabular}

Sumber: Pengolahan data primer 2018

Berdasarkan tabel diatas dapat dijelaskan bahwa pendapatan dan pekerjaan masyarakat di Kecamatan Pahae Julu, jika dilihat dari pendapatansampingan terhadap kebutuhan masyarat yang menjawab cukup sebanyak 66 orang (77\%) dan kurang cukup sebanyak 20 orang $(23 \%)$.

2. Lingkungan (Pencemaran Air)

a. pH Air (Derajat Keasaman)

pH atau derajat keasaman yaitu logaritma dan kepekatan ion-ion $\mathrm{H}$ (hidrogen) yang terlepas dalam suatu cairan. pH Air dapat dilihat pada tabel di bawah ini :

Tabel 8

Hasil Pengujian pH Sungai Batang Toru

\begin{tabular}{|c|l|r|r|c|}
\hline $\begin{array}{c}\text { Titik } \\
\text { Sampel }\end{array}$ & \multicolumn{1}{|c|}{$\begin{array}{c}\text { Daerah } \\
\text { PengambilanSampel }\end{array}$} & $\begin{array}{c}\text { Hasil } \\
\text { Pengujian } \mathrm{pH} \\
\text { air } \\
(\mathrm{mg} / \mathrm{I})\end{array}$ & $\begin{array}{c}\text { Baku } \\
\text { Mutu } \\
\mathrm{pH} \text { air } \\
(\mathrm{mg} / \mathrm{I})\end{array}$ & Keterangan \\
\hline 1 & $\begin{array}{l}\text { Kontrol (Daerah } \\
\text { sebelum PT. SOL) }\end{array}$ & 10 & $6-9$ & $\mathrm{~T}$ \\
\hline 2 & Daerah Perusahaan & 14 & $6-9$ & $\mathrm{~T}$ \\
\hline 3 & Daerah Permukiman & 13 & $6-9$ & $\mathrm{~T}$ \\
\hline 4 & Daerah Pertanian & 13 & $6-9$ & $\mathrm{~T}$ \\
\hline
\end{tabular}

Sumber: HasilUji Labor 2018

Ket: $\mathrm{T}=$ Tercemar, $\mathrm{TC}=$ Tidak Tercemar 
pH air Sungai Batang Toru pada titik sampel 1 yaitu $10 \mathrm{mg} / \mathrm{I}$, titik sampel 2 yaitu $14 \mathrm{mg} / \mathrm{I}$, titik sampel 3 yaitu $13 \mathrm{mg} / \mathrm{I}$ dan titik sampel 4 yaitu $13 \mathrm{mg} / \mathrm{I}$ dengan kondisi tercemar. b. COD (Chemical Oxygen Demand) COD (Chemical Oxygen Demand) merupakan jumlah oksigen yang dibutuhkan untuk mengoksidasi atau menguraikan zat organik dan anorganik dengan menggunakan bahan oksidasi. Hasil COD dapat dilihat pada tabel di bawah ini “

Tabel 9

Hasil Pengujian COD Sungai Batang Toru

\begin{tabular}{|c|l|r|r|c|}
\hline $\begin{array}{c}\text { Titik } \\
\text { Sampel }\end{array}$ & $\begin{array}{c}\text { Daerah Pengambilan } \\
\text { Sampel }\end{array}$ & $\begin{array}{c}\text { Hasil } \\
\text { Pengujian } \\
\text { COD } \\
(\mathrm{mg} / \mathrm{I})\end{array}$ & $\begin{array}{c}\text { Baku } \\
\text { Mutu } \\
\text { COD } \\
(\mathrm{mg} / \mathrm{I})\end{array}$ & Keterangan \\
\hline 1 & $\begin{array}{l}\text { Kontrol (Daerah } \\
\text { sebelum PT. SOL) }\end{array}$ & 4 & 25 & TC \\
\hline 2 & Daerah Perusahaan & 11,2 & 25 & TC \\
\hline 3 & Daerah Permukiman & 25 & 25 & TC \\
\hline 4 & Daerah Pertanian & 17 & 25 & TC \\
\hline
\end{tabular}

Sumber: HasilUji Labor 2018

Ket: $\mathrm{T}=$ Tercemar, $\mathrm{TC}=$ Tidak Tercemar

\section{COD (Chemical Oxygen}

Demand) pada titik sampel 1 yaitu 4 $\mathrm{mg} / \mathrm{I}$, titik sampel 2 yaitu $11,2 \mathrm{mg} / \mathrm{I}$, titik sampel 3 yaitu $25 \mathrm{mg} / \mathrm{I}$ dan titik sampel 4 yaitu $17 \mathrm{mg} / \mathrm{I}$ dengan kondisi tidak tercemar.

c. BOD (Biochemical Oxygen Demand)
BOD (Biochemical Oxygen Demand) merupakan jumlah bahan organik yang dibutuhkan untuk mengoksidasi atau menguraikan bahan organik oleh mikroorganisme air sehingga menjadi bentuk anorganik stabil. Hasil BOD dapat dilihat pada tabel di bawah ini:

Tabel 10

Hasil Pengujian BOD Sungai Batang Toru

\begin{tabular}{|c|c|c|c|c|}
\hline $\begin{array}{c}\text { Titik } \\
\text { Sampel }\end{array}$ & $\begin{array}{c}\text { Daerah Pengambilan } \\
\text { Sampel }\end{array}$ & $\begin{array}{c}\text { Hasil } \\
\text { Pengujian } \\
\text { BOD } \\
(\mathrm{mg} / \mathrm{I})\end{array}$ & $\begin{array}{c}\text { Baku } \\
\text { Mutu } \\
\text { BOD } \\
(\mathrm{mg} / \mathrm{I})\end{array}$ & Keterangan \\
\hline 1 & Kontrol (Daerah & 1,28 & 3 & TC \\
\hline
\end{tabular}




\begin{tabular}{|l|l|r|r|c|}
\hline & sebelum PT. SOL) & & & \\
\hline 2 & Daerah Perusahaan & 3,58 & 3 & $\mathrm{~T}$ \\
\hline 3 & Daerah Permukiman & 8 & 3 & $\mathrm{~T}$ \\
\hline 4 & Daerah Pertanian & 5,44 & 3 & $\mathrm{~T}$ \\
\hline
\end{tabular}

Sumber: HasilUji Labor 2018

Ket: $\mathrm{T}=$ Tercemar, $\mathrm{TC}=$ Tidak Tercemar

\section{BOD (Biochemical Oxygen}

Demand) pada titik sampel 1 yaitu $1,28 \mathrm{mg} / \mathrm{I}$, titik sampel 2 yaitu 3,58 $\mathrm{mg} / \mathrm{I}$, titik sampel 3 yaitu $8 \mathrm{mg} / \mathrm{I}$ dan titik sampel 4 yaitu $5,44 \mathrm{mg} / \mathrm{I}$. Di titik sampel 1 tidak tercemar sedangkan titik sampel 2-4 tercemar.

\section{d. DO (Oksigen Terlarut)}

DO atau oksigen terlarut, pada dasarnya merupakan oksigen yang berasal dari udara yang melarut kedalam air. Hasil DO dapat dilihat pada tabel di bawah ini :

Tabel 11

Hasil Pengujian DO Sungai Batang Toru

\begin{tabular}{|c|l|r|r|c|}
\hline $\begin{array}{c}\text { Titik } \\
\text { Sampel }\end{array}$ & $\begin{array}{c}\text { Daerah Pengambilan } \\
\text { Sampel }\end{array}$ & $\begin{array}{c}\text { Hasil } \\
\text { Pengujian DO } \\
(\mathrm{mg} / \mathrm{I})\end{array}$ & $\begin{array}{c}\text { Baku } \\
\text { Mutu } \\
\text { DO (mg/I) }\end{array}$ & Keterangan \\
\hline 1 & $\begin{array}{l}\text { Kontrol (Daerah } \\
\text { sebelum PT. SOL) }\end{array}$ & 7,57 & 4 & $\mathrm{~T}$ \\
\hline 2 & Daerah Perusahaan & 7,67 & 4 & $\mathrm{~T}$ \\
\hline 3 & Daerah Permukiman & 7,27 & 4 & $\mathrm{~T}$ \\
\hline 4 & Daerah Pertanian & 7,54 & 4 & $\mathrm{~T}$ \\
\hline
\end{tabular}

Sumber: Hasil Uji Labor 2018

Ket: $\mathrm{T}=$ Tercemar, $\mathrm{TC}=$ Tidak Tercemar

DO pada titik sampel 1 yaitu 7,57 mg/I, titik sampel 2 yaitu 7,67 mg/I, titik sampel 3 yaitu $7,27 \mathrm{mg} / \mathrm{I}$ dan titik sampel 4 yaitu $7,54 \mathrm{mg} / \mathrm{I}$ dengan kondisi tercemar. e. Nitrat

Nitrat merupakan bentuk nitrogen yang berperan sebagai nutrien utama bagi pertumbuhan tanaman dan alga.

Hasil nitrat dapat dilihat pada tabel di bawah ini :

Tabel 12

HasilPengujianNitrat Sungai Batang Toru

\begin{tabular}{|c|c|c|c|c|}
\hline & Daerah Pengambilan & Hasil & Baku & \multirow{2}{*}{ Titik } \\
Sampel & Sampel & Pengujian & Mutu & Keterangan \\
& & Nitrat & Nitrat & \\
& & $(\mathrm{mg} / \mathrm{I})$ & $(\mathrm{mg} / \mathrm{I})$ & \\
\hline
\end{tabular}




\begin{tabular}{|c|l|r|r|c|}
\hline 1 & $\begin{array}{l}\text { Kontrol (Daerah } \\
\text { sebelum PT. SOL) }\end{array}$ & $<0,5$ & 10 & TT \\
\hline 2 & Daerah Perusahaan & $<0,5$ & 10 & TT \\
\hline 3 & Daerah Permukiman & $<0,5$ & 10 & TT \\
\hline 4 & Daerah Pertanian & $<0,5$ & 10 & TT \\
\hline
\end{tabular}

Sumber: Hasil Uji Labor 2018

Ket: $\mathrm{T}=$ Tercemar, $\mathrm{TC}=$ Tidak Tercemar

Nitrat pada titik sampel 1 yaitu $<0,5 \mathrm{mg} / \mathrm{I}$, titik sampel 2 yaitu $<0,5 \mathrm{mg} / \mathrm{I}$, titik sampel 3 yaitu $<0.5 \mathrm{mg} / \mathrm{I}$ dan titik sampel 4 yaitu $<0.5 \quad \mathrm{mg} / \mathrm{I}$ dengan kondisi tercemar.

\section{f. Posfat}

Posfat dalam perairan adalah dalam bentuk orthoposfat yang membahas tentang kesuburan perairan.Hasil Posfat dapat dilihat pada tabel di bawah ini

Tabel 13

Hasil Pengujian Posfat Air Sungai Batang Toru

\begin{tabular}{|c|l|r|r|c|}
\hline $\begin{array}{c}\text { Titik } \\
\text { Sampel }\end{array}$ & $\begin{array}{c}\text { Daerah Pengambilan } \\
\text { Sampel }\end{array}$ & \multicolumn{1}{|c|}{$\begin{array}{c}\text { Hasil } \\
\text { Pengujian } \\
\text { Posfat } \\
(\mathrm{mg} / \mathrm{I})\end{array}$} & $\begin{array}{c}\text { Baku } \\
\text { Mutu } \\
\text { Posfat } \\
(\mathrm{mg} / \mathrm{I})\end{array}$ & Keterangan \\
\hline 1 & $\begin{array}{l}\text { Kontrol (Daerah } \\
\text { sebelum PT. SOL) }\end{array}$ & 0,81 & 0,2 & $\mathrm{~T}$ \\
\hline 2 & Daerah Perusahaan & 1,35 & 0,2 & $\mathrm{~T}$ \\
\hline 3 & Daerah Permukiman & 1,98 & 0,2 & $\mathrm{~T}$ \\
\hline 4 & Daerah Pertanian & 2,13 & 0,2 & $\mathrm{~T}$ \\
\hline
\end{tabular}

Sumber: Hasil Uji Labor 2018 Ket: T=Tercemar, TC=Tidak Tercemar

Posfat pada titik sampel 1 yaitu $<0,81 \mathrm{mg} / \mathrm{I}$, titik sampel 2 yaitu $<1,35 \mathrm{mg} / \mathrm{I}$, titik sampel 3 yaitu $<1,98 \mathrm{mg} / \mathrm{I}$ dan titik sampel 4 yaitu $<2,13 \mathrm{mg} / \mathrm{I}$ dengan kondisi tercemar.

\section{PENUTUP (KESIMPULAN)}

Berdasarkan hasil penelitian Analisis Dampak PT. Sarulla Operational Limited (SOL) Panas Bumi Terhadap Ekonomi dan Lingkungan Masyarakat Kecamatan Pahae Julu Kabupaten Tapanuli
Utara, maka dapat diambil kesimpulan sebagai berikut :

1. Dampak Positif bahwa keberadaan PT. SOL memberikan peningkatan terhadap perekonomian baik itu pekerjaan maupun pendapatan masyarakat kecamatan Pahae Julu.

2. Dampak Negatif bahwa keberadaan PT. SOL merusak lingkungan yaitu sungai Batang Toru yang sudah 
tercemar akibat limbah panas bumi tersebut.

\section{DAFTAR PUSTAKA}

Adamu Mustapha and Balabe Usman Getso, 2014. Sources and Pathway of Environmental Pollutants into Surface Water Resources: A review. Journal of Environments, Assian online Journal Publishing Group. ISSN: 2313-660 X, Vol. 1, No.2, Pg.54-59.

Akinbile, C.O and Yussoff M.S; 2011. Environmental Impact of Leachate Pollution on Groundwater Supplies in Akure, Nigeria, International Journal of Environmental Science and Development, Vol. 2, No. 1, ISSN: 20100264

Azheri. 2012. Corporate Social Responsbility : Dari Voluntary Menjadi

Mandatory. Jakarta: Rajawali Press.

Badan Pusat Statistik. 2016. Data Kabupaten Tapanuli Utara Dalam Angka 2016.

Esrey, S.A, J.B. Potash, I. Roberts and C. Shiff, 1991. Effects of Improved Water Supply and Sanitation on Ascariasis, Diarrhea, Dracuncihasis, Hookworm Infection, sechistosomiasus and trachoma : Bull, WHO, Vol 69, No 5: pg 609-621.

Everpure, 1997. Evaluation of Groundwater Quality Characteristics in Lagos City. Journal of Applied Science, Vol 7 ,No. 13. Pg. 1780-1784, 2007.
Farid, S., 2002. Water Pollution and Its Effects on Human Health in Rural Areas of Faisalabad Pak, Journal of Applied Sciences, Volume 2, No. 8. Pg.822-825.

FEPA, 1991. Guidelines and Standards for Environmental Pollution Control in Nigeria. Federal Environmental Protection Agency, Lagos, Vol 3. No 6, Pg. 230-232.

Fewtrell, L and J.M. Colford, 2004. Water, Sanitation and Hygiene: Interventions and Diarrhea. A systematic Reviewand Meta-Analysis, Water Supply and Sanitation Board. The World Bank Retrieve from: http/www/worldbank.org/htp/ pubsdiscussion/fewtrell\&colfo rdjuly.

Harrington, W.A. Krupnick and W.Spofford, 1989. The Economic Losses of a Water Borne Disease Outbreak. Journal of Urban Economics, Vol 25, Pg.116-137.

Hertz-Piccioto I.H.M. Arrighi, and S.W. HU, 2000. Does Arsemic Exposure Increase the Risk of Circulatory Disease American Journal of Epidemial, Vol 2, No. 151 Pg:174-181.

Hung, M.F. and Shaw, 2004. A Trading-Raton System for Trading Water Pollution Discharge Permits. Journal of Environmental Economy and Management. Vol.1, No. 49, Pg.83-102.

Ilegbodu, V.A, Christatensen, B.L, Wise R.A., Ilegbodu A.E, Kale O.O, 1987. Sources of 
Drinking Water Supply and Transmissionof Guinea-worm Disease in Nigeria, Ann Trop Med. Parasitology, Vol 81 No. 6 : Pg.713-718.

Jimoh, H.I and I.P Ifabiyi, 2007. Ilorin, Nigeria Hay Tee Press and Publishing Co.Ltd

Sanchez-Choliz J and R. Duarte, 2005. Water Pollution in the Spanish Economy: Analyst of Sensitivity to Production and Environment Constraints. Ecol; Vol. 53 No. 3 Pg: 325338.
Sudjana. 2007. Metode dan Teknik

Pembelajan dengan Statistik. Jakarta : Bumi Aksara.

World Bank, 1990. Towards the Development of an Environmental Action Plan for Nigeria. Report Number 9002-UNI World Bank, Washington, DC

Yang, G;C. Gangcai and C. Youngguan, 2004. The Econometric Assessment of Losses by water Pollution in Chongqing, South West China, Chinese Journal of Geoch, Vol 23 (1). Pg. 94100. 